Article

\title{
Research on Rural Nonpoint Source Pollution in the Process of Urban-Rural Integration in the Economically-Developed Area in China Based on the Improved STIRPAT Model
}

\author{
Hongjun Dai ${ }^{1,2, *}$, Tao Sun ${ }^{1}$, Kun Zhang ${ }^{1,3}$ and Wen Guo ${ }^{1}$
}

1 College of Economic and Management, Nanjing University of Aeronautics and Astronautics, Nanjing 211106, China; E-Mails: nuaastao@163.com (T.S.); zhkun_033@163.com (K.Z.); guowen_870608@163.com (W.G.)

2 College of Economic and Management, Huainan Normal University, Huainan 232000, China

3 College of Information Science and Technology, Shandong University of Political Science and Law, Jinan 250014, China

* Author to whom correspondence should be addressed; E-Mail: dhj@hnnu.edu.cn; Tel.: +86-554-686-2873.

Academic Editor: Yongrok Choi

Received: 26 June 2014 / Accepted: 31 December 2014 / Published: 12 January 2015

\begin{abstract}
The process of urban-rural integration has led to severe ecological environmental pollution in rural areas of China, particularly in the economically-developed areas. This is an urgent issue to be solved. We select Jiangsu Province as a case study. From the perspective of the population, economic scale, energy consumption and financial support, we perform an empirical study of rural non-point source pollution problems in the process of urbanization based on the improved STIRPAT model. We apply the ridge regression method to avoid the multicollinearity of the variables in the STIRPAT model. The results show that the technological level, the size of the population and financial support are important factors affecting rural non-point source pollution. Therefore, we believe that technical progress, transformation of the mode of production and increasing the scale of financial support in rural areas are effective measures to solve the current rural nonpoint source pollution.
\end{abstract}

Keywords: urban-rural integration; rural non-point source pollution; STIRPAT model; ridge regression method; measures 


\section{Introduction}

With the development of the economy, environmental pollution has become more and more serious in China. Environmental protection has become a priority of government work. Additionally, more and more scholars have begun to study China's pollution control problems from different angles [1-3]. In recent years, the rural environmental pollution problem has increasingly intensified with the speeding up of the urban-rural integration, especially in developed regions.

Urban-rural integration is centered on cities, small towns serving as a link, based on the country, the rural areas driven by urban areas and township-promoted agriculture, which established a new urban-rural relationship of mutual benefit and reciprocity, as well as mutual promotion, coordinated development and promoted common prosperity. Urban-rural integration is not the basic driving force to ensure China's future economic growth, but a fundamental way to seek coordinated development between urban and rural areas, as well as to solve the "three agricultural problems" (referring in particular to agriculture, rural areas and farmer issues). From years of practice, urban-rural integration has greatly promoted the development of rural non-agricultural industries, achieving rural lifestyle urbanization and stimulating the free flow of the factors of production, narrowing the urban-rural gap. However, it has also exacerbated the extent of environmental pollution in rural areas of China, especially in developed regions. Rural pollution has a serious impact on regional economic development, endangers people's health and, in turn, hinders urban-rural integration. As one of the largest and fastest-growing economic regions in China, Jiangsu Province was the first region to promote urban-rural integration starting in 1983. Tremendous achievements have been accomplished, but rural environmental problems remain.

As can be seen in Table 1, the pollution problems of rural areas in Jiangsu Province gradually increased along with the development of the economy, which directly causes the deterioration of our natural environment. It was shown that the rural area's surface water was slightly polluted in nine monitoring stations in the 2011 Report on the State of the Environment in Jiangsu Province in China. Additionally, it shows that the water quality was exceeded in 2011 by $30 \%$. It is necessary to analyze the rural non-point source pollution and put forward a targeted approach, for the purpose of facilitating the smooth implementation of the urban and rural integration process and of achieving sustainable development goals. Thus, many scholars have begun to focus on the rural environmental pollution in the process of urban-rural integration.

Non-point source pollution has four main features: private ownership, complex and diverse causes, great harm and a large influence scope. Therefore, it is difficult to clean up non-point source pollution in rural areas. The research on rural non-point source pollution control abroad began in the 1980s, mainly focused on technical measures, control theory, economic policy, etc. In 1991, two economists, Grossman and Krueger, proposed the famous EKC (Environmental Kuznets Curve) curve for describing the relationship between environmental population and per capita income [4]. Bell and Russell presented the view that the quantitative measurement of non-point source pollution is the foundation of the sewage charges and the issuance of sewage discharge permits [5]. Ribaudo et al., Isik, Russel and Clark, Egli and Steger and Speir studied the feasibility of economic means and policy instruments to solve rural non-point source pollution [6-10]. They also discussed the implementation difficulties and corresponding countermeasures. Kaplowitz et al. studied non-point source pollution 
control using the selected experimental investigation methods and by understanding the public's preferences [11]. The results show that the involvement of stakeholders can increase the public recognition of the pollution control plan, thereby improving the effectiveness of pollution control. Camacho-Cuena et al. and Cason et al. also studied non-point source pollution from different aspects through experimentation [12,13].

Table 1. Economic and environmental data of Jiangsu Province in China (1990-2009).

\begin{tabular}{|c|c|c|c|c|}
\hline Index & Units & 1990 & 2009 & $\begin{array}{c}\text { Annual Average } \\
\text { Growth \% }\end{array}$ \\
\hline Urbanization rate of population & $\%$ & 21.56 & 55.60 & 3.71 \\
\hline Agriculture GDP ${ }^{1}$ & Billion Yuan & 355.17 & 798.74 & 6.24 \\
\hline The proportion of non-agriculture & $\%$ & 72.0 & 94.6 & 1.57 \\
\hline The proportion of non-agriculture labor & $\%$ & 38.48 & 67.15 & 3.73 \\
\hline Rural households per capita net income & Yuan & 263.81 & 786.71 & 9.91 \\
\hline Rural Engel coefficient & $\%$ & 52.30 & 39.20 & -1.25 \\
\hline COD emissions ${ }^{2,3}$ & Tons & 64.20 & 96.88 & 2.55 \\
\hline TP emissions ${ }^{2,4}$ & Tons & 4.78 & 8.33 & 3.71 \\
\hline TN emissions ${ }^{2,5}$ & Tons & 54.29 & 72.87 & 1.71 \\
\hline
\end{tabular}

${ }^{1}$ Constant prices in $1978 ;{ }^{2}$ research data from the College of Resources and Environment, Nanjing Agricultural University; ${ }^{3} \mathrm{COD}$ indicates chemical oxygen demand; ${ }^{4} \mathrm{TP}$ indicates total phosphorus; ${ }^{5} \mathrm{TN}$ indicates total nitrogen.

Non-point source pollution has also been studied from the technology and economic policy viewpoint in China. Li et al. thought that it showed an inverted U-shaped curve between fertilizer non-point source pollution and macroeconomic growth [14]. There are several key factors of the fertilizer non-point source pollution in rural areas, including the level of residents' wealth, the proportion of nonfarm employment of farmers, the urban-rural dualistic environmental management system, and so on. Guo and Sun have also researched the EKC curve between rural non-point source pollution and economic growth empirically in different ways [15]. Gao et al. calculated the equivalent pollution load and equivalent pollution index of Shandong Province in 2007, using the "Equivalent pollution load method" [16]. Yang et al. investigated the measures that could solve the problem of rural non-point source pollution and proposed an optimized management model about small watershed water quality [17]. Jin et al. investigated the acceptability of Macao residents to a solid waste management policy through the selection model [18]. Ge and Zhou proposed that China's policy of fertilizer price control and fiscal subsidies to farmers led to the distortion of the fertilizer market, which increased the emission of agricultural fertilizer non-point source pollutants [19].

Tremendous changes have occurred in the development scale, industrial structure, standards of living and lifestyle in rural areas due to urban-rural integration. These changes will have a great influence on rural non-point pollution. However, only a few studies have explored this area. Xiao thought that the environment should be protected through creating beautiful villages and ecological construction [20]. Luo took the rural areas of Chongqing as an example and proposed a measure of rural pollution control based on the perspective of urban and rural overall development [21]. Fei et al. discussed the ecological environmental issues in the process of urban-rural integration and presented the 
countermeasures correspondingly [22]. Fu took the rural areas of Changtu in Liaoning Province as an example, studied the status and issues of rural environmental governance and also put forward some measures on the issues [23]. As can be seen from the literature above, there has been a great deal of achievement in urban-rural integration. However, few of these works involve rural environmental pollution. If any, they put emphasis on the theoretical analysis and countermeasures instead of empirical analysis. This paper applies the improved STIRPAT model to research the rural non-point source pollution in the process of urban-rural integration. We use the ridge regression method to estimate the model parameters in order to avoid collinearity between the variables of the study based on theoretical analysis. Additionally, we use the ridge regression method to estimate model parameters in order to avoid collinearity between the variables of the study. In this paper, Jiangsu Province is selected as the study area, due to the fact that it is one of the most developed areas in China, the urban-rural integration in Jiangsu is representative of China and it has great influence. This paper empirically investigates the factors influencing rural non-point environmental pollution in the process of urban-rural integration and confirms the main factors that can influence rural non-point pollution. Finally, this paper provides the theoretical basis for rural environmental governance measures.

\section{Analysis of Environmental Effects on the Construction of Urban and Rural Integration}

\subsection{Analysis of Population Factors}

The rural population continues to decline, resulting in the decrement of the employment of the rural population with the urban and rural integration. Because of the lack of a rural labor force, the traditional mode of agricultural production is very hard to continue. Thus, farmers will increase their input of pesticides and fertilizers, machinery and other production factors as much as possible to replace the labor input for agricultural production. According to the statistics, the rural population has been reduced from $53,079,600$ to $34,296,800$ from 1990 to 2009 , while the proportion of the employment of the rural population decreased from $74.69 \%$ to $58.81 \%$. Fertilizer use increased from $2,217,900$ tons to $3,440,000$ tons, and = pesticide use increased from 79,800 tons to 92,300 tons. Plastic film use rose from 35,400 tons to 94,300 tons at the same time. It is inevitable that non-point source pollution will continuously increase due to the wide use of chemicals.

\subsection{Analysis of Economic Factors}

Rural areas had experienced rapid economic development with urban and rural integration. Currently, chemicals, mainly fertilizers, pesticide, and plastic film significantly contribute to the development of agriculture in China. The increase of the agricultural economic scale means a large consumption of chemicals. At the same time, the income of the farmer's increases accordingly. Therefore, farmers will require better environmental quality. This will promote the improvement of environmental quality.

\subsection{Analysis of Financial Factors}

The government will pay more attention to the development of rural areas in the process of urban-rural integration. The government will provide funds and technology to rural areas. The 
technical level of agricultural production will be increased. The farmers will reduce the use of fertilizer, pesticide and other factors of production. By increasing the expenditure in rural areas, we can effectively support construction in rural areas, including environmental infrastructure. Once the environmental infrastructure increases, the processing capacity for environmental pollutants will be enhanced and non-point source pollutants will decrease. Consequently, the ecological environment can be improved at the same time. The increased expenditure is also able to increase funding for the publicity of environmental protection and to promote rural residents' environmental awareness, thereby reducing pollutant emissions.

\section{Model, Variables and Method}

\subsection{Improved STIRPAT Model}

Ehrlich and Holdren put forward the IPAT model $(I=P A T)$ to research carbon emissions in 1971 [24]. I represents the amount of carbon emissions; $P$ represents population size; $A$ represents the degree of affluence; and $T$ represents the technical level or energy efficiency. Dietz and Rose established the STIRPAT model $\left(I=\mathrm{a} P^{b} A^{c} T^{d} e\right)$ based on the IPAT model in 1994 [25]. The model allows for adjustment and improvement according to different research purposes. Therefore, the applicability of this model is stronger.

The model was applied extensively to research environmental issues. However, few researchers have applied it to rural non-point source pollution. We apply it to rural non-point source pollution in the process of urban-rural integration in this paper. We improved and decomposed the related variables of the STIRPAT model according to the analysis conclusions above. $P$ represents the rural population size. $A$ represents the size of the economy. $T$ represents energy efficiency. Finally, we introduce a new index, $F$, to represent the financial support for rural areas. In order to verify the existence of the EKC curve in rural non-point source pollution, we establish a non-linear model with reference to the method of York (2003) [26]. We take the logarithm of the variables to eliminate the heteroscedasticity of the data and to explain the results better. The improved STIRPAT model is as follows:

$$
\ln I=\ln a+b_{1}(\ln P)+\left[c_{1}(\ln A)+c_{2}(\ln A)^{2}\right]+d(\ln T)+e(\ln F)
$$

\subsection{Variables and Data}

The research data on $C O D$ emissions per year, $T P$ emissions per year and $T N$ emissions per year is cited from the research data of the College of Resources and Environmental Science, Nanjing Agricultural University [27]. All other research data are taken from the "Jiangsu Statistical Yearbook" (from 1990 to 2009). We discount the data value indicators according to the 1978 value to eliminate the influence of price changes.

At first, we apply principal components analysis methods to analyze the three kinds of non-point pollutants. The results show that the coefficient of the KMO (Kaiser-Meyer-Olkin) test is 0.748 , which indicates that the variables correlate closely with each other and are suitable to be analyzed with principal components. The first principal component takes into account $97.30 \%$ of the original data. 
Finally, we get a pollutant comprehensive value according to its proportion in the first principal component at last.

Pollutant comprehensive value $=0.3349 \times C O D+0.3295 \times T N+0.3356 \times T P$

Table 2. Research variables and research data.

\begin{tabular}{cccccc}
\hline & $\boldsymbol{I}$ & $\boldsymbol{P}$ & $\boldsymbol{A}$ & $\boldsymbol{T}$ & $\boldsymbol{F}$ \\
\hline & $\begin{array}{c}\text { Pollutant } \\
\text { Comprehensive Value }\end{array}$ & $\begin{array}{c}\text { Rural } \\
\text { Population }\end{array}$ & $\begin{array}{c}\text { Rural per } \\
\text { GDP }\end{array}$ & $\begin{array}{c}\text { Efficiency of the } \\
\text { Use of Chemical } \\
\text { Fertilizer }\end{array}$ & $\begin{array}{c}\text { the Proportion of } \\
\text { Fiscal Expenditure } \\
\text { on Agriculture }\end{array}$ \\
\hline 1990 & 40.993303 & 5307.96 & 671.83 & 30.83 & 8.37 \\
1991 & 41.641868 & 5255.96 & 685.40 & 28.63 & 8.17 \\
1992 & 42.814612 & 5267.48 & 671.83 & 27.47 & 8.65 \\
1993 & 44.77097 & 5293.69 & 742.48 & 25.77 & 10.96 \\
1994 & 48.108065 & 5287.53 & 915.99 & 24.63 & 7.92 \\
1995 & 51.597425 & 5136.93 & 1043.15 & 22.83 & 7.90 \\
1996 & 54.239611 & 5167.66 & 1022.49 & 21.70 & 7.57 \\
1997 & 51.841629 & 5014.22 & 972.63 & 20.61 & 7.47 \\
1998 & 54.87332 & 4919.99 & 972.63 & 19.89 & 7.25 \\
1999 & 55.840211 & 4693.04 & 962.95 & 22.47 & 7.20 \\
2000 & 57.111186 & 4286.43 & 1043.15 & 22.44 & 5.87 \\
2001 & 58.181257 & 4221.72 & 1085.72 & 22.15 & 5.93 \\
2012 & 58.902019 & 4081.68 & 1130.03 & 21.95 & 5.94 \\
2003 & 58.22738 & 3942.12 & 1261.43 & 21.88 & 6.29 \\
2004 & 58.363574 & 3851.52 & 1540.71 & 21.36 & 5.77 \\
2005 & 58.937756 & 3699.88 & 1652.43 & 21.07 & 5.83 \\
2006 & 59.137562 & 3631.31 & 1719.86 & 20.89 & 6.08 \\
2007 & 55.676315 & 3568.27 & 1978.31 & 20.77 & 7.58 \\
2008 & 57.358569 & 3508.02 & 2230.54 & 20.77 & 8.50 \\
2009 & 59.251325 & 3429.68 & 2321.57 & 20.44 & 10.04 \\
\hline
\end{tabular}

\subsection{Ridge Regression Method}

The multiple regressions are sensitive to the collinearity. The coefficient standard deviation will falsely estimate at the higher degree of collinearity based on the least squares regression method (OLS). The ridge regression method is improved based on the least squares regression method and can avoid the collinearity of the model. Therefore, we apply it in this paper.

\section{Empirical Results and Analysis}

\subsection{Unit Root Tests}

In order to avoid the phenomenon of "spurious regression", we perform ADF (Augmented Dickey-Fuller test) unit root tests for all variables using EVIEW6.0 to examine their stationarity. We present test results as shown in Table 3. 
Table 3. ADF unit root test results.

\begin{tabular}{|c|c|c|c|c|c|}
\hline Variables & Test Type & Original Sequence & Test Type & First Difference & Conclusion \\
\hline $\ln I$ & $(\mathrm{C}, \mathrm{T}, 0)$ & -1.232 & $(\mathrm{C}, 1,7)$ & $-13.674 * * *$ & $\begin{array}{l}\text { First order } \\
\text { stationary }\end{array}$ \\
\hline \multirow[t]{2}{*}{$\ln A$} & $(\mathrm{C}, \mathrm{T}, 0)$ & -2.375 & $(\mathrm{C}, \mathrm{T}, 1)$ & $-3.670 * *$ & First order \\
\hline & & & & & stationary \\
\hline \multirow[t]{2}{*}{$\ln T$} & $(\mathrm{C}, \mathrm{T}, 0)$ & -2.146 & $(\mathrm{C}, \mathrm{T}, 7)$ & $-20.269 * * *$ & First order \\
\hline & & & & & stationary \\
\hline \multirow[t]{2}{*}{$\ln P$} & $(\mathrm{C}, \mathrm{T}, 0)$ & -2.280 & $(\mathrm{C}, 0,7)$ & $-4.400 * * *$ & First order \\
\hline & & & & & stationary \\
\hline$F$ & $(0,0,0)$ & 0.198 & $(0,0,1)$ & $-2.428 * *$ & First order stationary \\
\hline
\end{tabular}

As can be seen from the test results, not all of the original sequences of variables are stable. After the first difference, the time sequence data of total variables reject the original hypothesis at the level of significance of $5 \%$ and consider that they are first-order difference stationary sequences.

\subsection{Co-Integration Tests}

Since total variables are $I$ (one) sequences, the co-integration test can be carried out to determine whether there are long-run equilibrium relationships between them. The Johansen co-integration test method is used in this article, because it is more suitable for a multivariate co-integration test, and the test potential is higher than the EG (Engle-Granger) two-step method. The optimal lag order of VAR (Vector Auto-regression Model) (P) is two, determined by using the AIC (Akaike Information Criterion) and the SC (Schwarz information criterion) information criterion. Therefore, the optimal lag order of the Johansen co-integration test is one. Accordingly, the results of the Johansen co-integration test are obtained in Table 4.

Table 4. Test results of the Johansen co-integration approach.

\begin{tabular}{cccc}
\hline Original Hypothesis & Eigenvalues & Trace Statistic & Critical Value (5\%) \\
\hline None $* *$ & 0.9986 & 271.6813 & 83.9371 \\
At most $1 * *$ & 0.9888 & 153.9545 & 60.0614 \\
At most $2 * *$ & 0.9097 & 73.0420 & 40.1749 \\
At most $3 * *$ & 0.5534 & 29.7621 & 24.2760 \\
At most $4 * *$ & 0.4856 & 15.2536 & 12.3209 \\
At most 5** & 0.1670 & 3.2894 & 3.1299 \\
\hline \multicolumn{4}{r}{ * indicates that original hypothesis is rejected at the 5\% level. }
\end{tabular}

From the results of Johansen co-integration, we can see that both the trace test and max-eigenvalues test reject the original hypothesis at the 5\% confidence level, suggesting that there are co-integration relationships between total variables. 


\subsection{Estimation Results of the Model}

Due to the existence of a co-integration relationship between total variables, we estimate the parameters of Model (1). We apply a ridge regression method with Maekmay software 5.0 to avoid the multicollinearity of the model variables. We get the ridge regression coefficient and the ridge trace plot after setting up the ridge parameter $K$ from zero to 0.50 , and a step of 0.05 . We present test results as shown in Table 5 and Figure 1.

Total regression coefficients of independent variables have a large variation range when the ridge parameter goes from zero to 0.05 . These are the abnormal changes caused by multicollinearity. The regression coefficients of independent variables tends to be stable when the ridge parameter is larger than 0.05 . The bigger the ridge parameter, the greater the standard error of the model. Therefore, we set the ridge parameter to 0.05 . At last, we get the parameters' estimated values. We present test results as shown in Table 6.

As can be seen from the estimation results, the model works well. The adjusted $R^{2}$ of the model is greater than 0.900 , which means that the explanation capacity of all of the variables reaches above $90 \%$. The empirical results are consistent with what we expect. The technological factor is the highest. The second is the size of the population. The third is the prosperity and financial support. Lastly is the size of economy. The EKC curve in rural non-point source pollution does not exist currently.

Table 5. Estimated results of the ridge regression.

\begin{tabular}{cccccccc}
\hline $\boldsymbol{K}$ & $\boldsymbol{S D}$ & $\boldsymbol{C}$ & $\boldsymbol{\operatorname { n } I}$ & $\boldsymbol{\operatorname { l n }} \boldsymbol{A}$ & $(\boldsymbol{\operatorname { l n }} \boldsymbol{A})^{\mathbf{2}}$ & $\ln \boldsymbol{T}$ & $\boldsymbol{F}$ \\
\hline 0.00 & 0.0301 & -2.9573 & -0.5073 & 3.6578 & -0.2611 & -0.5218 & 0.0055 \\
0.05 & 0.0384 & 7.5076 & -0.1983 & 0.0181 & 0.0002 & -0.5926 & -0.0209 \\
0.10 & 0.0398 & 6.8697 & -0.1582 & 0.0284 & 0.0013 & -0.5355 & -0.0219 \\
0.15 & 0.0411 & 6.5396 & -0.1415 & 0.0342 & 0.0019 & -0.4962 & -0.0221 \\
0.20 & 0.0423 & 6.3314 & -0.1330 & 0.0377 & 0.0022 & -0.4659 & -0.0219 \\
0.25 & 0.0435 & 6.1843 & -0.1282 & 0.0401 & 0.0024 & -0.4412 & -0.0216 \\
0.30 & 0.0446 & 6.0723 & -0.1253 & 0.0418 & 0.0026 & -0.4204 & -0.0213 \\
0.35 & 0.0457 & 5.9825 & -0.1233 & 0.0430 & 0.0027 & -0.4025 & -0.0209 \\
0.40 & 0.0469 & 5.9078 & -0.1219 & 0.0439 & 0.0028 & -0.3868 & -0.0205 \\
0.45 & 0.0479 & 5.8439 & -0.1207 & 0.0446 & 0.0028 & -0.3728 & -0.0201 \\
0.50 & 0.0490 & 5.7880 & -0.1198 & 0.0450 & 0.0029 & -0.3603 & -0.0197 \\
\hline
\end{tabular}

Table 6. Estimation results of the model.

\begin{tabular}{ccc}
\hline & Coefficients & Standardized Coefficient \\
\hline$C$ & 7.5076 & -0.2585 \\
$\ln P$ & -0.1983 & 0.0553 \\
$\ln A$ & 0.0181 & 0.0071 \\
$(\ln A)^{2}$ & 0.0002 & -0.5732 \\
$\ln T$ & -0.5926 & -0.2386 \\
$\ln F$ & -0.0209 & \\
Adjusted $R^{2}$ & 0.907 & \\
$F$ & $38.100 * * *$ &
\end{tabular}




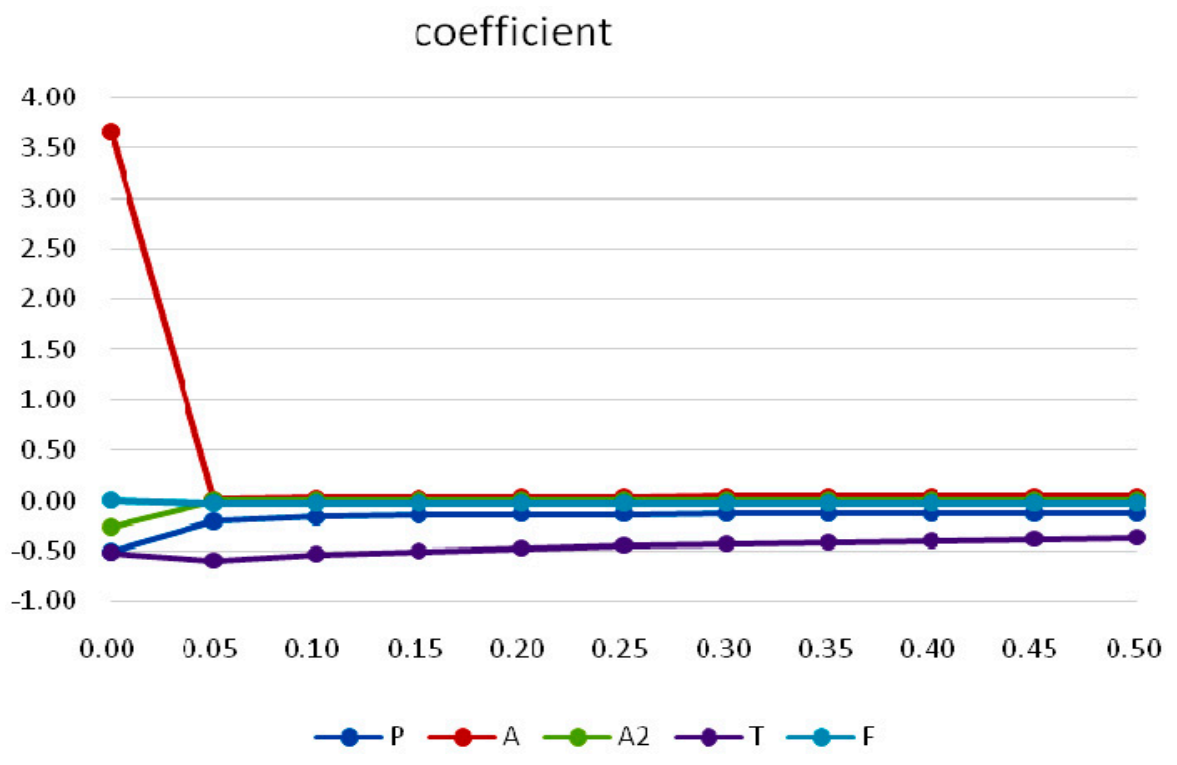

Figure 1. Ridge trace plot.

\section{Conclusions and Policy Suggestions}

According to the data about economic development and environmental pollution from 1990 to 2009 in Jiangsu Province, we apply the improved STIRPAT model and the ridge regression method to study the rural pollution problem in a developed area in the process of urban-rural integration. The results show that technological level and the size of the population are important factors to reduce rural non-point source pollution. Financial support can reduce rural non-point source pollution, too. Accordingly, we put forward the following policy suggestions:

(1) Balance urban and rural development, speed up industrial adjustment and speed up scientific and technological progress. Currently, an extensive and predatory development model has inspired the increase in agricultural nonpoint source pollution. Hence, balancing urban and rural development, taking economic and policy measures to guide rural industrial structure adjustment, introducing green industry and eco-industries instead of polluting non-agricultural industries and speeding up scientific and technological progress will reduce rural non-point source pollution effectively.

(2) Increase financial support and improve rural environmental infrastructure. The dual urban-rural environmental protection system is an important factor for ineffective rural non-point source management. For a long time, the focus of China's environmental protection work has been in big cities, large industries and large projects, while rural environmental protection basically has remained in a marginalized status. In recent years, though the situation has improved, it still cannot meet the needs of the current pollution situation. Therefore, the government should take on policies of various forms: on the one hand, increasing financial input to environmental infrastructure in rural areas and improving the capacity to control pollution; and on the other, setting up a special fund for rural governance. In this way, the trend of the deterioration of the rural ecological environment can be reversed. 
Of course, there are some limitations in this paper that need to be improved in future research. Due to variability of the data, such as population urbanization and the proportion of non-farm labor, being unstable, they are not included in the model for the empirical analysis; therefore, the study of the influencing factors is not comprehensive.

\section{Acknowledgments}

This study was supported in part by: the Ministry of Education Foundation for Humanities and Social Science (No. 11YJA790133), the Jiangsu Province Foundation for Philosophy and Social Sciences (No. 12EYA001), the Bidding Project of the Research Center for Resource-based Cities' Development of Huainan Normal University (No. SK2014A099), the Program for Innovative Research Team in Huainan Normal University, the CNAC Foundation for Generalized Virtual Economics (No. GX2012-1023(Y)).

\section{Author Contributions}

All of the authors made contributions to the work in this paper. Tao Sun and Hongjun Dai designed the research. Hongjun Dai contributed to model development, data collection. Kun Zhang and Wen Guo analyzed the data. Tao Sun provided guidance for writing this paper. Hongjun Dai wrote the paper. All authors have read and approved the final manuscript. We would like to acknowledge the reviewers for the comments that enhanced the quality of the manuscript.

\section{Conflicts of Interest}

The authors declare no conflict of interest.

\section{References}

1. Zhang, N.; Kong F.; Choi, Y.; Zhou, P. The effect of size-control policy on unified energy and carbon efficiency for Chinese fossil fuel power plants. Energy Policy 2014, 70, 193-200.

2. Zhang, N.; Choi, Y. Total-factor carbon emission performance of fossil fuel power plants in China: A metafrontier non-radial Malmquist index analysis. Energy Econ. 2013, 40, 549-559.

3. Choi, Y.; Zhang, N.; Zhou, P. Efficiency and abatement costs of energy-related $\mathrm{CO}_{2}$ emissions in China: A slacks-based efficiency measure. Appl. Energy 2012, 98, 198-208.

4. Grossman, G.M.; Krueger, A.B. Environment Impacts of a North American Free Trade Agreement. Available online: http://www.nber.org/papers/w3914 (accessed on 30 December 2014).

5. Bell, R.G.; Russell, C. Environmental Policy for Developing Countries. Issues Sci. Technol. 2002, 69, 63-70.

6. Ribaudo, M.; Horan, R.D.; Smith, M.E. Economics of Water Quality Protection from Nonpoint Sources: Theory and practice; Economic Research Service: Washington, DC, USA, 1999.

7. Isik, H.B.; Sohngen, B. Performance-Based Voluntary Group Contracts for Nonpoint-Source Water Pollution; Ohio State University: Columbus, OH, USA, 2003. 
8. Russell, C.S.; Clark, C.D. Economic Instruments and Nonpoint Source Water Pollution; Biswas, A.K., Tortajada, C., Braga, B., Eds.; Springer: Berlin, Germany, 2006.

9. Egli, H.; Steger, T.M. A Dynamic Model of the Environmental Kuznets Curve: Turning Point and Public Policy. Environ. Resour. Econ. 2007, 36, 15-34.

10. Khanna, M.; Speir, C. Motivations for Proactive Environmental Management. Sustainability 2013, 5, 2664-2692.

11. Kaplowitz, M.D.; Lupi, F. Stakeholder preferences for best management practices for non-point source pollution and stormwater control. Landsc. Urban Plan. 2012, 3, 364-372.

12. Camacho-Cuena, E. Requate, T. The regulation of non-point source pollution and risk preferences: An experimental approach. Ecol. Econ. 2012, 1, 179-187.

13. Cason, T.N.; Gangadharan, L. Empowering neighbors versus imposing regulations: An experimental analysis of pollution reduction schemes. J. Environ. Econ. Manag. 2012, 9, 87-96.

14. Li, T.; Zhang, F.; Hu, H. Authentication of the Kuznets Curve in Agriculture Non-point Source Pollution and Its Drivers Analysis. China Popul. Resour. Environ. 2011, 21, 118-123.

15. Guo, W.; Sun, T. Empirical Research of Rural Non-point Source Pollution Based on the Theory of "EKC". Hunan Agric. Sci. 2012, 23, 117-120.

16. Gao, X.; Jiang, L.; Li, X.; Liu, Z.; Xu, Y.; Wei, J. Using Equivalent Standard Pollution method to evaluate impacts of agricultural non-point pollution resources on water environment in Shandong Province. Chin. J. Ecol. Agric. 2010, 18, 1066-1071.

17. Yang, Y.; Yan, B. Optimal Non-point Source Pollution Control Practices for a Small Watershed. J. Ecol. Rural. Environ. 2011, 27, 11-15.

18. Jin, J.; Wang, Z. Choice Experiment Method and Its Application to Solid Waste Management in Macao. Environ. Sci. 2006, 27, 821-826.

19. Ge, J.; Zhou, S. Does Factor Market Distortions Stimulate the Agricultural Non-oint Source Pollution? A Case Study of Fertilizer. Issues Agric. Econ. 2012, 3, 92-100.

20. Xiao, J. To promote integral construction of cities and villages to accordinate the development of economy, society and environment. Environ. Pollut. Control 2004, 26, 198-202.

21. Luo, D.; Bai, J.; Zhu, L. Study on the Cause and Strategy of Country Pollution in Chongqing by the Angle of Viewing Urban and Country Plan as a Whole. Ecol. Econ. 2009, 4, 166-169.

22. Fei, Y.; Zhang, J.; Cheng, Q. Strengthening Eco-Environmental Protection during the Process of Urban-rural Integration Construction. Pollut. Control Technol. 2010, 23, 89-93.

23. $\mathrm{Fu}, \mathrm{S}$. How to improve rural living environment and accelerate the integration of urban and rural. Agric. Econ. 2012, 4, 41-42.

24. Ehrlich, P.R.; Holdrens, J.P. Impact of population growth. Science 1971, 171, 1212-1217.

25. Dietz, T.; Rosa, E.A. Rethinking the environmental impacts of population, affluence and technology. Hum. Ecol. Rev. 1994, 1, 277-300.

26. York, R.; Rosa, E.A.; Dietz, T. STIRPAT, IPAT and ImPACT: Analytic Tools for Unpacking the Driving Forces of Environmental Impacts. Ecol. Econ. 2003, 46, 351-365. 
27. Jiang, F.; Cui, C. Temporal and spatial characteristics and source apportionment of agricultural non-point source pollution in Jiangsu province based on inventory analysis. J. Anhui Agric. Univ. 2012, 39, 961-967.

(C) 2015 by the authors; licensee MDPI, Basel, Switzerland. This article is an open access article distributed under the terms and conditions of the Creative Commons Attribution license (http://creativecommons.org/licenses/by/4.0/). 